\title{
INTERVENÇÃO FISIOTERAPÊUTICA NA PREVENÇÃO DOS DORT EM AUXILIARES DE LIMPEZA
}

\author{
Lucas Lima Ferreira Fisioterapeuta. Mestrando em \\ Fisioterapia pela Universidade Estadual \\ Paulista, campus de Presidente \\ Prudente.
Fernanda Mardegan Delatim Fisioterapeuta. Docente do curso de Fisioterapia da Fundação Educacional de Fernandópolis. \\ Forlan Luciano Vilela Fisioterapeuta graduado pela Fundação \\ Educacional de Fernandópolis.
Andreia Dias Fisioterapeuta. Mestre em Saúde Coletiva pela Universidade Estadual Paulista, campus de Botucatu. Docente do curso de Fisioterapia da FEF.

\begin{abstract}
Resumo
Objetivo:Descrever uma intervenção fisioterapêutica com foco na prevenção dos distúrbios osteomusculares relacionados ao trabalho (DORT) sobre auxiliares de limpeza. Metodologia: Tratou-se de um estudo exploratório e descritivo de cunho qualitativo, cuja amostra foi composta de quatro funcionárias de uma escola técnica estadual, localizada no interior do Estado de São Paulo. O protocolo de intervenção consistiu do trabalho de educação em saúde, aplicação de exercícios laborais compensatórios, orientações posturais e a descrição das opiniões das funcionárias sobre a atuação da fisioterapia preventiva no ambiente de trabalho.Resultados: Foi verificado um ganho de conhecimento e uma melhora na condição de saúde/trabalho e na qualidade de vida das funcionárias. Conclusão:A partir dos resultados obtidos, concluiu-se que a prevenção é o caminho mais correto na atuação com trabalhadores, pois acaba com um ciclo no qual, os mesmos ficam negligenciados no saber sobre os DORT e os torna agente ativo na transformação de seu ambiente de trabalho.
\end{abstract}

Palavras-chave: Doenças ocupacionais; Fisioterapia; Prevenção.

\section{INTERVENTION PREVENTION IN PHYSIOTHERAPEUTIC WMSD AUXILIARY IN CLEANING}

\begin{abstract}
Objective: To describe a physical therapy intervention focused on the prevention of work-related musculoskeletal disorders (MSDs) on cleaning aids. Methods: This was an exploratory and descriptive qualitative character, whose sample consisted of four employees of a state technical school, located within the State of São Paulo. The intervention protocol consisted of work in health education, application exercises labor compensatory, postural orientation and description of the views of employees on the preventive role of physiotherapy in the workplace. Results: We observed a gain of knowledge and an improvement in health status / work and quality of life of employees. Conclusion: From the results obtained, it was concluded that prevention is the most correct way in acting with workers, because it ends with a cycle in which they are neglected in the know about MSDs and become active agent in the transformation of their work environment.
\end{abstract}

Keywords: Occupational diseases; Physiotherapy; Prevention. 


\section{INTRODUÇÃO}

Os distúrbios osteomusculares relacionados ao trabalho (DORT) são afecções de músculos, tendões, sinóvias, nervos, fáscias e/ou ligamentos, isoladas ou combinadas, com ou sem degeneração de tecidos. ${ }^{(1)}$ Estas lesões atingem em maiores proporções - mas não somente - os membros superiores, a região escapular e a região cervical, sendo sua origem ocupacional, decorrendo (de forma combinada ou não) do uso repetido ou forçado de grupos musculares e da manutenção de postura inadequada. ${ }^{(1-5)}$

As estruturas músculo-esqueléticas passam a ser alvo frequente destas agressões independentemente do tipo de atividade ou do produto fabricado, do processo e organização do trabalho. ${ }^{(6)}$ Nesse contexto, os DORT têm se constituído em grande problema da Saúde Pública em muitos dos países industrializados. ${ }^{(3)}$ Essas doenças representam mais da metade das doenças ocupacionais, contabilizando em 2001, segundo o Centro de Estudos da Saúde do Trabalhador (CESAT), 65\% dos casos de diagnósticos de doenças ocupacionais. ${ }^{(5)}$

Em relação ao gênero, o acometimento quantitativo maior dos DORT, se expressa, sobretudo, através da mulher trabalhadora, fato diretamente relacionado não a uma "suposta" propensão biológica, mas, ao papel e à forma de inserção da mulher nas divisões social e sexual do trabalho. ${ }^{(7)}$ Além disso, a incidência dos DORT é maior entre os trabalhadores jovens; as mulheres são as mais atingidas, prevalecendo a faixa etária de 20 a 39 anos. ${ }^{\left({ }^{8}\right)}$

A prevenção é uma das ações que têm sido mais discutidas atualmente no que diz respeito ao combate dos DORT; porém suas causas estão sendo reconhecidas e poucas ações preventivas têm sido realizadas. ${ }^{(9)} \mathrm{E}$, devido ao grande destaque desses distúrbios entre as afecções ocupacionais, a atuação da fisioterapia nas empresas, cresce a cada dia pela descoberta da importância do investimento em ações preventivas e por não estar o fisioterapeuta limitado, apenas, a curar e reabilitar. ${ }^{(5)}$

Diante do exposto, este estudo teve como objetivo,descrever uma intervenção fisioterapêutica na prevenção dos DORT em funcionárias com o cargo de auxiliares de limpeza de uma instituição de ensino técnico.

\section{METODOLOGIA}

O presente estudo tem caráter exploratório e descritivo, de cunho qualitativo, embasado na metodologia da pesquisa-ação. A pesquisa envolve a integração dos 
pesquisadores e sujeitos, no levantamento de problemas sobre os DORT, e, na elaboração e aplicação de uma intervenção fisioterapêutica focada no controle/prevenção dos DORT.

Esta pesquisa foi realizada em uma instituição de ensino técnico denominado Escola Técnica Estadual (ETEC) campus Fernandópolis, localizada na cidade de Fernandópolis, região noroeste do estado de São Paulo.

Foram selecionadas quatro funcionárias do setor de limpeza, todas do sexo feminino, que após esclarecimento dos objetivos da pesquisa, receberam e assinaram um Termo de Consentimento Livre e Esclarecido, desenvolvido após o parecer favorável do Comitê de Ética em Pesquisa da Fundação Educacional de Fernandópolissob protocolonúmero 54/2009.

A presente pesquisa foi desenvolvida em dois momentos distintos e fundamentais, descritos a seguir:

Primeiro momento: foi a elaboração e aplicação de um programa de intervenção fisioterapêutico focado na prevenção e/ou controle dos DORT, diante dos problemas levantados mediante observação do posto de trabalho.

Segundo momento: foi à descrição das opiniões dos sujeitos da pesquisa, no que se refere à intervenção fisioterapêutica, realizada pelos graduandos de fisioterapia, por meio da aplicação de um questionário com questões abertas.

A análise dos dados do segundo momento foifeita de forma qualitativa, a fim de demonstrar claramente os resultados, favorecendo assim uma melhor compreensão e interpretação dos resultados.

$\mathrm{Na}$ análise dos dados do segundo momento processamos a leitura detalhada de todas as respostas emitidas pelos sujeitos pesquisados. Foram selecionadas e recortadas às respostas ou expressões que foram repetidas com mais frequência ou que foram colocadas com maior ênfase pelos sujeitos pesquisados. Procederam-se à análise e interpretação dos achados, resultados (opiniões) dos sujeitos da pesquisa sobre a atuação dos graduandos de fisioterapia.

\section{RESULTADOS E DISCUSSÃO}

\section{Primeiro Momento}

A ação preventiva direcionou-se a realização do trabalho de educação em saúde, por meio de palestras e cartazes afixados no posto de trabalho, exercícios laborais e a observação do posto de trabalho para uma orientação prática sobre postura. Na sequência serão esclarecidas as intervenções fisioterapêuticas executadas neste estudo. 
As palestras foram norteadas por referências bibliográficas, com o objetivo de solucionar algumas necessidades de conhecimento sobre: doenças ocupacionais, estratégias preventivas como melhor forma de intervenção e atuação do fisioterapeuta na empresa.É importante salientar que a atenção e o interesse das funcionárias envolvidas foramtotais, despertando-as para a importância da fisioterapia preventiva no ambiente de trabalho. Segundo Gazzinelliet al., ${ }^{(10)}$ palestras permitem educar os trabalhadores para a saúde e para os problemas de saúde baseado na hipótese de que vários problemas de saúde são resultantes da precária situação educacional da população, carecendo de medidas corretivas e educativas.

Os cartazes são uma forma de prevenção utilizada pelo fisioterapeuta do trabalho, a fim de informar aos trabalhadores sobre posturas adequadas para o levantamento e transporte de cargas, posturas corretas na posição sentada e posturas que devem ser evitadas, além de outras que não foram enfocadas neste trabalho (Figura 1).

Estes cartazes foram elaborados e fixados na ETEC com o objetivo de demonstrar aos sujeitos da pesquisa quais as posturas consideradas corretas e incorretas na realização das Atividades de Vida Diária (AVD), nas quais se incluem posturas relacionadas ao trabalho exercido pelas funcionárias pesquisadas, como, o levantamento e o transporte de cargas, entre outras. Os cartazes foram fixados nas dependências do prédio escolar na tentativa de orientação e lembrete para os sujeitos da pesquisa. 
Figura 1 - Cartaz relacionado às posturas corretas e incorretas

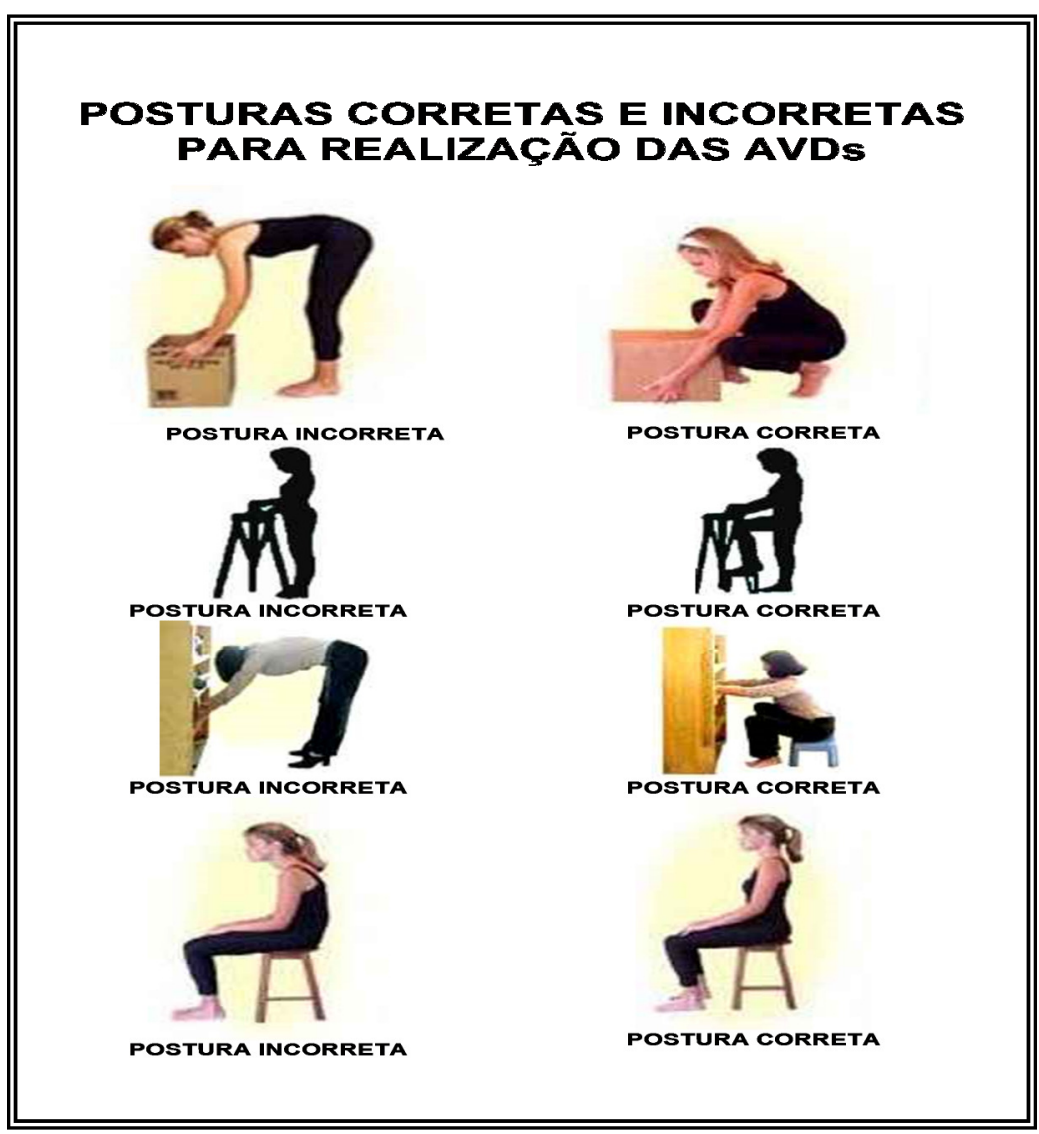

Fonte: Acervo pessoal.

\section{Exercícios Laborais}

Os exercícios laborais foram aplicados enfocando cabeça, pescoço e membros superiores (MMSS) na tentativa de prepará-los para a execução adequada de suas tarefas.

Foram aplicados os exercícios compensatórios, realizados durante a jornada de trabalho, com o objetivo de trabalhar os músculos correspondentes e relaxar os músculos que estão em contração durante a maior parte da jornada de trabalho, ${ }^{(11,12)}$ sendo que, os benefícios desta atividade incluem: diminuição dos níveis de ansiedade e estresse, aumento da flexibilidade, redução das tensões musculares, melhora na circulação, favorecimento da conscientização corporal, redução do risco de DORT e auxílio no desempenho perante o trabalho. ${ }^{(13)}$

Cabe ressaltar aqui, que como foram feitos os exercícios compensatórios, não foi realizado o aquecimento, pois os sujeitos da pesquisa já haviam iniciado suas atividades laborais, estando, portanto, pré-aquecidas.

O programa de exercícios laborais foi composto de alongamentos, exercícios de fortalecimento muscular e relaxamento, que perfizeram um total de 30 minutos por sessão, 
três vezes por semana, durante três meses. O protocolo de alongamentos constou de alongamentos para cervical (flexão, extensão, inclinações lateral direita e esquerda) e para MMSS (deltóide anterior e posterior, trapézio médio, rombóides, peitorais, bíceps braquiais, tríceps braquiais, flexores e extensores de punho), sempre instruindo as funcionárias a respiração correta durante o exercício. Alguns foram realizados individualmente e outros em duplas, variando as mesmas a cada dia de aplicação. Foram utilizados 15 minutos para o alongamento sempre com músicas apropriadas. Segundo a literatura, ${ }^{(14)}$ alguns dos benefícios dos alongamentos são: eliminam, reduzem e/ou evitam encurtamento do sistema muscular, eliminam e/ou reduzem nódulos musculares, mantêm e/ou aumentam a flexibilidade, diminuem risco de lesão músculo-articular, aumentam relaxamento muscular e circulação sangüínea, melhoram coordenação e postura estática e dinâmica.

Em seguida, foram aplicados exercícios de fortalecimento muscular com resistência mecânica para os MMSS, nas quais as funcionárias utilizaram alteres de meio quilograma. Foram trabalhados os seguintes grupos musculares: bíceps braquiais, tríceps braquiais, deltóides anterior, médio e posterior e peitoral. Os exercícios constaram de três séries de dez repetições cada para cada grupo muscular trabalhado, sendo realizados em 10 minutos e com músicas específicas para o fortalecimento.Os benefícios dos exercícios de fortalecimento muscular são, entre outros, restaurar, melhorar ou manter a força, a potência e a resistência muscular à fadiga; aumentar a força do conjunto de tecidos conjuntivos; contribuir para maior densidade mineral óssea; diminuir sobrecarga nas articulações durante a atividade física; favorecer a melhora do equilíbrio, promover aumento da massa muscular magra. ${ }^{(15)}$

Ao final de cada dia de aplicação dos exercícios laborais aplicou-se o relaxamento muscular através de exercícios leves de alongamento e relaxamento em ambiente com iluminação propícia e a leitura de mensagens contendo frases de otimismo e da importância da vivência em grupo. Foi realizada nos cinco minutos finais do tempo determinado para a intervenção terapêutica.Os exercícios de relaxamento proporcionam um aumento da sensação de descanso para os músculos mais exigidos em determinada tarefa promovendo a eliminação de substâncias tóxicas. ${ }^{(16)}$ Ressalva especial pode ser feita à leitura da mensagem, que foi uma complementação feita pelos pesquisadores sendo que não existem referências para tal na literatura. 


\section{Orientações Posturais}

As orientações posturais foram realizadas com base na observação feita no posto de trabalho dos sujeitos da pesquisa durante realização de suas atividades, focando-se em um trabalho educativo em relação às posturas ideais para o desenvolvimento das atividades funcionais, evitando a sobrecarga do sistema músculo-esquelético. As orientações foram realizadas durante o expediente de trabalho nos setores da escola durante uma hora.

Em relação à limpeza de mobiliários, foram verificados movimentos incorretos como flexão de tronco com extensão de membros inferiores (MMII). A orientação feita foi manter sempre o tronco ereto em posição neutra e realizar movimentos de flexo-extensão de MMII para esta atividade.

Quanto à tarefa de varrer o chão de uma sala de aula, observou-se o movimento incorreto de flexão de tronco com extensão de MMII que causa sobrecarga à coluna vertebral. Após esta observação os sujeitos foram orientados a fazer atividades como varrer e passar pano sempre com a coluna em posição neutra e realizar movimentos de flexo-extensão de MMII, além de instrução especial em adequar à ferramenta de trabalho.

Asfuncionárias realizaram a limpeza das janelas da ETEC com movimento incorreto de flexão com abdução de ombro acima de $90^{\circ}$. As funcionárias foram orientadas a não realizar movimentos que ultrapassem os $90^{\circ}$ de elevação de ombros e adaptarem sua atividade com vassouras acopladas a cabos mais longos para limpeza de locais altos.

Com relação à atividade de empilhamento e carregamento de mobiliários (cadeiras) feitos pelos sujeitos da pesquisa, ficou evidente um conjunto de movimentos incorretos como flexão de tronco com extensão de MMII, elevação de peso, superior ao suportado pela funcionária, em nível de tronco, compensando com extensão de tronco. A orientação proposta foi manter o tronco em posição neutra, realizar movimentos de flexo-extensão de MMII, carregar peso proporcional ao biótipo corporal sempre em nível de quadril e nunca realizar compensação no tronco para não aumentar a sobrecarga sobre a coluna vertebral.

$\mathrm{Na}$ atividade de lavar o pano em um balde colocado no chão,pode-se observar o movimento incorreto de flexão de tronco com extensão de MMII. Foi proposto como orientação, manter o tronco ereto em posição neutra e realizar o movimento de flexão de joelhos para a atividade em questão. Uma segunda orientação foi colocar o balde em locais em que o mesmo fique na altura dos quadris da funcionária, como por exemplo, uma carteira. 
De acordo com Carneiro et al., ${ }^{(17)}$ é cada vez maior o número de pessoas com problemas posturais, devido à ação de agente estressores e externos no cotidiano de trabalho. A educação postural, nesse contexto, possibilita a pessoa proteger ativamente segmentos móveis de lesões, dentro das condições de vida diária e profissional, tanto no plano estático como no dinâmico, possibilitando a realização de atividades dentro de um espaço de segurança. ${ }^{(18)}$

Segundo Nascimento e Moraes, ${ }^{(13)}$ o levantamento e transporte de cargas tem sido uma das causas mais comuns de lesões osteomusculares em trabalhadores, devido à diferença nas capacidades físicas individuais e substituições de trabalhadores homens por mulheres, sendo necessário, assegurar a energia e o compromisso das pessoas com novas formas de trabalho e de comportamento.

Um estudo feito com profissionais do sexo feminino de um serviço de apoio (limpeza) demonstrou que a maioria tem consciência dos esforços e desgastes físicos necessários para execução de suas atividades. ${ }^{(19)}$ Este grupo de trabalhadores adota no exercício de suas atribuições posturas e mecânica corporal inadequada, as quais poderão acarretar a curto e longo prazo danos em seu sistema músculo-esquelético. ${ }^{(19)}$

\section{Segundo Momento}

No segundo momento da pesquisa, retratou-se a descrição das opiniões dos sujeitos sobre a atuação da fisioterapia na empresa. Para tanto, foi aplicado um formulário para verificar qual o impacto das ações e intervenções desenvolvidas. A seguir são apresentados os resultados deste momento, através de quadros representativos de cada questão, com as respostas dos sujeitos da pesquisa.

Quadro 1 - Respostas dos sujeitos sobre se houve melhoras na condição de saúde ou trabalho

\section{Respostas sim (100\%)}

melhorou o astral; agora sinto mais ânimo para o trabalho; percebi uma grande melhora na minha postura; melhorou o ânimo, as dores diminuíram, enfim melhorou tudo.

\section{Respostas não (0\%)}

Nenhuma 
No Quadro 1, as respostas evidenciaram melhora por parte dos sujeitos da pesquisa na condição de saúde/trabalho com a intervenção preventiva aplicada. Observa-se que houve maior satisfação na questão da saúde, como descrito nessa resposta "melhorou o ânimo, as dores diminuíram, enfim melhorou tudo" e também na questão do trabalho, "agora sinto mais ânimo para o trabalho". Esses relatos evidenciaram a necessidade de implantações de métodos preventivos definitivos, para melhorar a qualidade de trabalho e também de vida das funcionárias.

Quadro 2 - Respostas dos sujeitos sobre se passou a ter ou melhorou seu conhecimento sobre as doenças relacionadas ao trabalho.

\section{Respostas sim $(100 \%)$}

.... sobre as doenças do trabalho, posições corretas de trabalho; ficamos mais informadas do assunto (doenças do trabalho, posturas corretas, sintomas); a importância do alongamento para os músculos; como agachar para pegar objetos que estão no chão.

\section{Respostas não (0\%)}

Nenhuma

No Quadro 2, as respostas dos sujeitos da pesquisa demonstraram que antes da intervenção não dispunham de certos conhecimentos referentes aos DORT, sendo que, com o trabalho desenvolvido pelos graduandos de fisioterapia, estes sujeitos adquiriram os conhecimentos básicos para o desenvolvimento adequado de suas atividades laborais. Assim sendo, as funcionárias pesquisadas relataram alguns conhecimentos aprendidos, "sobre as doenças do trabalho", "a posições corretas de trabalho", "como agachar para pegar objetos...”. Relatos como esses são de suma importância para certificar a necessidade que os trabalhadores possuem em conhecer as doenças ocupacionais, suas causas, fatores de risco e as formas de preveni-las. 
Quadro 3 - Respostas dos sujeitos se consideram importante a presença do fisioterapeuta na empresa.

\section{Respostas sim $(100 \%)$}

...porque aprendemos como trabalhar corretamente, posições de trabalho adequadas, alongamentos; porque melhora a qualidade de vida; melhorar as posturas e corrigir todos os atos dos exercícios incorretos em relação ao trabalho; melhora a qualidade de vida e de trabalho.

\section{Respostas não (0\%)}

Nenhuma

No Quadro 3, as respostas evidenciaram que os sujeitos da pesquisa consideram de suma importância a presença do fisioterapeuta na empresa, fato observado em relatos como “aprendemos como trabalhar corretamente”, “melhora a qualidade de vida”. É possível observar aqui, que os trabalhadores perceberam a importância da presença de um fisioterapeuta na ambiente de trabalho, e que este atua em favor à saúde dos funcionários, atuando nos níveis de promoção, prevenção e reabilitação.

Quadro 4 - Respostas dos sujeitos sobre se aprenderam ou não algum assunto. E caso sim, qual (is)

\section{Respostas sim (100\%) trabalhar corretamente. \\ Respostas não (0\%) \\ Nenhuma}

como fazer o alongamento, a posição correta de trabalho; trabalhar corretamente, que doenças acarreta, que o psicológico é fundamental; trabalhar corretamente, abaixar sempre com os joelhos dobrados, varrer com vassoura de cabo auto e observar o ombro reto, passar pano com um pouco do joelho dobrado e com a coluna um pouco extensa para frente;

No Quadro 4 as respostas evidenciaram que os sujeitos da pesquisa adquiriram conhecimento sobre os assuntos abordados no trabalho preventivo aplicado. Relataram em suas respostas que aprenderam como "fazer o alongamento", "a posição correta de trabalho", “o que as doenças acarretam”. Através desta bagagem de aprendizado saberão como se prevenir contra o desenvolvimento dos sinais e sintomas das doenças ocupacionais. 


\section{CONCLUSÃO}

A partir desta pesquisa, podê-se perceber que a atuação preventiva do fisioterapeuta no contexto ocupacional é de suma importância, pois concede aos trabalhadores conhecimentos indispensáveis sobre os DORT e uma melhor condição de vida/saúde no trabalho.

Assim, pode-se concluir que a prevenção é o caminho mais correto na atuação com trabalhadores, pois acaba com um ciclo no qual, os mesmos ficam negligenciados no saber sobre os DORT e os torna agente ativo na transformação de seu ambiente de trabalho.

\section{REFERÊNCIAS}

1. Oliveira RMR. A abordagem das lesões por esforços repetitivos / distúrbios osteomusculares relacionados ao trabalho - LER/DORT no Centro em Saúde do Trabalhador do Espírito Santo - CRST/ES [dissertação]. Rio de Janeiro: Escola Nacional de Saúde Pública; 2001.

2. Barbosa LGA. Fisioterapia preventiva nos distúrbios osteomusculares relacionados ao trabalho - DORT: a fisioterapia do trabalho aplicada. Rio de Janeiro: Guanabara Koogan; 2002.

3. Brasil. Ministério da Saúde. Instrução normativa INSS/DC, N. ${ }^{\circ} 98$ de 5 de dezembro de 2003.Atualização clínica das lesoes por esforços repetitivos (LER) / distúrbios osteomusculares relacionados ao trabalho (DORT).Diário Oficial [da] República Federativa do Brasil, Brasília, 2003.

4. Regis Filho GI, Michels G, Sell I. Lesões por esforços repetitivos/distúrbios osteomusculares relacionados ao trabalho em cirurgiões dentistas. RevBrasEpidemiol. 2006;9(3):346-59.

5. Santos APA,Santos DQ, Santos GG, Venceslau GF, Zimmermann ID, Mascarenhas MC. Atuação fisioterapêutica preventiva nos distúrbios osteomusculares relacionados ao trabalho. 2008. Disponível em:

http://www.institutoagilita.com.br/imagens/Atuacao_Fisioterapeutica_Preventiva_nos_Distur bios_Osteomusculares_relacionados_ao_Trabalho.pdf.

6. Renner JS. Prevenção de distúrbios osteomusculares relacionados ao trabalho. Boletim da Saúde. 2005;19(1):73-80.

7. Salim CA.Doenças do trabalho: exclusão, segregação e relações do gênero. São Paulo em perspect. 2003;17(1):11-24.

8. Wash IAP, Corral S, Franco RN, Canetti EEF, Alem MER, Coury HJCG. Capacidade para o trabalho em indivíduos com lesões músculo-esqueléticas crônicas. Revsaúde pública. 2004;38(2):149-56. 
9. Ribeiro KSQS. A atuação da fisioterapia na atenção primária à saúde - Reflexões a partir de uma experiência universitária. Fisioter.brasil. 2002;3(5):311-18.

10. Gazzinelli MF, Gazzinelli A, Reis DC, Penna CMM. Educação em Saúde: conhecimentos, representações sociais e experiências da doença. Cadsaúde pública. 2005;21(1):200-6.

11. Ramirez HZ, Accioly MF, Silva R, Mana VAM. Atuação da fisioterapia preventiva por meio da implantação da cinesioterapia laboral e da intervenção ergonômica, no setor de fechamento (costura) em indústria de colchões. RevInstCiênc Saúde. 2005;23(2):93-8.

12. Pereira ER, Freitas VRP. Cinesioprofilaxia: um fator de aumento da produtividade do cirurgião dentista. Rev Bras Ortop. 2002;59(6):366-97.

13. Nascimento NM, Moraes RAS. Fisioterapia nas empresas. $3^{\mathrm{a}}$ ed. Rio de Janeiro: Taba Cultural; 2000.

14. Martins CO, Duarte MFS. Efeitos da ginástica laboral em servidores da reitoria da UFSC. Rev. bras. ciênciamov. 2000;8(4):07-13.

15. Kisner C, Colby LA. Exercícios terapêuticos: fundamentos e técnicas. $4^{\mathrm{a}}$ ed. Barueri: Manole; 2005.

16.Deliberato PCP. Fisioterapia preventiva: fundamentos e aplicações. Barueri: Manole; 2002.

17. Carneiro JAO, Souza LM, Munaro HLR. Predominância de desvios posturais em estudantes de educação física da universidade estadual do sudoeste da Bahia. Rev. saúde com. 2005;1(2):118-23.

18. Braccialli LMP,Vilarta R. Aspectos a serem considerados na elaboração de programas de prevenção e orientação de problemas posturais. Rev.paul.educ. fís.2000;14(1):16-28.

19. Ferrari IG,Alberton IMDC, Paiano M, Radovanovic CAT. Avaliação da prevalência de dor músculo-esquelética nos trabalhadores do serviço de apoio de um hospital universitário. Arq. Apadec.2004;8(1):1-6. 